\title{
Article \\ The Involvement of Glucose in Hydrogen Gas-Medicated Adventitious Rooting in Cucumber
}

\author{
Zongxi Zhao, Changxia Li, Huwei Liu, Jingjing Yang, Panpan Huang and Weibiao Liao *(D) \\ College of Horticulture, Gansu Agricultural University, 1 Yinmen Village, Anning District, \\ Lanzhou 730070, China; zhaozongxi2021@163.com (Z.Z.); licxgsau5@163.com (C.L.); Ihwgsauedu@163.com (H.L.); \\ yangjingjing202108@163.com (J.Y.); huangpp2243739575@163.com (P.H.) \\ * Correspondence: liaowb@gsau.edu.cn; Tel.: +86-931-7632399; Fax: +86-931-7632155
}

check for updates

Citation: Zhao, Z.; Li, C.; Liu, H.;

Yang, J.; Huang, P.; Liao, W. The

Involvement of Glucose in Hydrogen Gas-Medicated Adventitious Rooting in Cucumber. Plants 2021, 10, 1937. https://doi.org/10.3390/

plants10091937

Academic Editor: John Hancock

Received: 19 August 2021

Accepted: 14 September 2021

Published: 17 September 2021

Publisher's Note: MDPI stays neutral with regard to jurisdictional claims in published maps and institutional affiliations.

Copyright: (C) 2021 by the authors. Licensee MDPI, Basel, Switzerland. This article is an open access article distributed under the terms and conditions of the Creative Commons Attribution (CC BY) license (https:/ / creativecommons.org/licenses/by/ $4.0 /)$.

\begin{abstract}
Hydrogen gas $\left(\mathrm{H}_{2}\right)$ and glucose $(\mathrm{Glc})$ have been reported as novel antioxidants and signal molecules involved in multiple biological processes in plants. However, the physiological roles and relationships of $\mathrm{H}_{2}$ and Glc in adventitious rooting are less clear. Here, we showed that the effects of different concentrations Glc $(0,0.01,0.05,0.10,0.50$ and $1.00 \mathrm{mM})$ on adventitious rooting in cucumber were dose-dependent, with a maximal biological response at $0.10 \mathrm{mM}$. While, the positive roles of hydrogen rich water ( $\mathrm{HRW}$, a $\mathrm{H}_{2}$ donor)-regulated adventitious rooting were blocked by a specific Glc inhibitor glucosamine (GlcN), suggesting that Glc might be responsible for $\mathrm{H}_{2}$-regulated adventitious root development. HRW increased glucose, sucrose, starch and total sugar contents. Glucose-6-phosphate (G6P), fructose-6-phosphate (F6P) and glucose-1-phosphate (G1P) contents were also increased by HRW. Meanwhile, the activities of sucrose-related enzymes incorporating sucrose synthase (SS) and sucrose phosphate synthase (SPS) and glucose-related enzymes including hexokinase $(\mathrm{HK})$, pyruvate kinase $(\mathrm{PK})$ and adenosine $5^{\prime}$-diphosphate pyrophosphorylase (AGPase) were increased by HRW. Moreover, HRW upregulated the expression levels of sucrose or glucose metabolism-related genes including CsSuSy1, CsSuSy6, CsHK1, CsHK3, CsUDP1, CsUDP1-like, CsG6P1 and CsG6P1-like. However, these positive roles were all inhibited by GlcN. Together, $\mathrm{H}_{2}$ might regulate adventitious rooting by promoting glucose metabolism.
\end{abstract}

Keywords: glucosamine; sucrose; starch; gene expression; sugar metabolism

\section{Introduction}

Adventitious roots (AR) are postembryonic roots which originate from the stem, leaf petiole and non-pericycle tissue of old roots [1]. Normally, inappropriate conditions including injury and stress promote AR formation. Recent results revealed that AR formation was positively regulated by plant hormones and signaling molecules, such as abscisic acid (ABA) [2], auxin [3], brassinolide (BR) [4], gibberellin (GA) [5], ethylene [6], hydrogen peroxide $\left(\mathrm{H}_{2} \mathrm{O}_{2}\right)$ [7], nitric oxide (NO) [8], carbon monoxide (CO) [9] and hydrogen sulfide $\left(\mathrm{H}_{2} \mathrm{~S}\right)$ [10] Additionally, molecular evidence illustrated that auxin- and ethylene-related genes and proteins are closely associated with the initiation and development of AR [11]. The complex responses regulated by these hormones, signaling molecules, genes and proteins are most likely to be achieved by a more detailed AR signaling process. However, whether there are some other novel singling molecule(s) involved in AR formation remains to be studied.

Hydrogen gas $\left(\mathrm{H}_{2}\right)$, colorless, tasteless and flammable, is the structurally simplest gas in nature. Recently, research on $\mathrm{H}_{2}$ has progressed from focusing on its role as a fuel to its role as matter that is able to regulate multiple biological functions in animals and plants. Treatment with $\mathrm{H}_{2}$ relieved brain damage and inflammation after traumatic brain injury in rats [12]. At the same time, it was reported that hydrogen therapy was a potential and effective treatment for exercise-induced injury in sports medicine [13]. In plants, $\mathrm{H}_{2}$ is considered as an important signaling modulator that functions in plant responses against 
salt, heavy metals, low temperatures and paraquat stresses [14]. $\mathrm{H}_{2}$ actively controls a series of plant growth and development stages including seed germination, seedling growth, adventitious rooting and root elongation [14]. In addition, hydrogen rich water (HRW) could defer postharvest ripening and aging of kiwifruit [15]. Interestingly, $\mathrm{H}_{2}$ can interact directly with specific signaling pathways, including $\mathrm{NO}, \mathrm{CO}$ and ethylene [16].

Starch is a ubiquitous storage polysaccharide in the plant kingdom. Adenosine $5^{\prime}$-diphosphate pyrophosphorylase (AGPase) is a key enzyme governing starch synthesis. In the process of plant metabolism, starch is hydrolyzed into monosaccharides such as glucose (Glc). Glc is an important member of monosaccharides which exists widely in animals and plants. Simultaneously, Glc is recognized as a central signaling molecule that balances the requirement of nutrient and energy in plants. Hexokinase (HK), as an enzyme in glycolysis, phosphorylates glucose to glucose-6-phosphate [17]. Both HKdependent and HK-independent glucose signal transduction pathways appear to coexist in plants [18]. Sucrose is synthesized using cytosolic phosphotriose as a substrate. Sucrose may then be transported to sink organs or it is cleaved by invertase to Glc and fructose [19]. Fructose-6-phosphate (F6P) and sucrose phosphate synthase (SPS) have been recognized as the rate-limiting products or enzymes in the process of sucrose synthesis [20]. Glc acts as a primary signal molecule in plant response against drought stress and heat stress [21]. Simultaneously, it was reported that Glc regulated a series of growth and development stages, including seed germination, seedling development, embryo development, cell division, stomatal movement, seed dormancy, leaf senescence and fruit ripening [22,23]. Previous results also elaborated that Glc significantly regulated AR development in Arabidopsis thaliana [24].

Previous studies have shown that both $\mathrm{H}_{2}$ and Glc regulate AR development in plants. However, there is no information regarding the crosstalk between $\mathrm{H}_{2}$ and Glc in adventitious rooting. The purpose of the research study was to investigate the roles and interaction of $\mathrm{H}_{2}$ and Glc in AR development. Deeper insights into the interplay of various signaling molecules with $\mathrm{H}_{2}$ will help provide a road-map for $\mathrm{H}_{2}$-regulated AR development.

\section{Results}

\subsection{Effect of Different Concentrations Glc on AR Development}

When compared with the control, $0.01 \mathrm{mM}$ Glc had no significant effect on root number (Table 1). However, treatments with $0.05,0.10$ and $0.50 \mathrm{mM}$ Glc significantly increased root number (Table 1). Root length was higher in $0.01,0.05,0.10$ and $0.50 \mathrm{mM}$ Glc treatments than in the control (Table 1). Compared to the control, $1.00 \mathrm{mM}$ Glc significantly inhibited both root number and root length. The results indicated that Glc treatment affected AR development in a dose-dependent manner. Among the different concentrations, the maximum root number and root length were observed at $0.10 \mathrm{mM}$ concentration of Glc (Table 1). Thus, $0.10 \mathrm{mM}$ Glc was used as a treatment for further studies during the rooting process.

Table 1. Effect of Glc on AR development in cucumber.

\begin{tabular}{ccc}
\hline Glc/mM & Root Number & Root Length $(\mathbf{m m})$ \\
\hline 0.00 & $3.21 \pm 0.18 \mathrm{c}$ & $4.99 \pm 0.18 \mathrm{~d}$ \\
0.01 & $3.91 \pm 0.12 \mathrm{c}$ & $6.97 \pm 0.44 \mathrm{c}$ \\
0.05 & $4.63 \pm 0.14 \mathrm{~b}$ & $8.04 \pm 0.13 \mathrm{~b}$ \\
0.10 & $6.95 \pm 0.05 \mathrm{a}$ & $9.69 \pm 005 \mathrm{a}$ \\
0.50 & $4.37 \pm 0.01 \mathrm{~b}$ & $7.06 \pm 0.25 \mathrm{c}$ \\
1.00 & $2.58 \pm 0.18 \mathrm{~d}$ & $4.06 \pm 0.44 \mathrm{e}$ \\
\hline
\end{tabular}

Effect of different concentrations Glc (0, 0.01, 0.05, 0.10, 0.50 and $1.00 \mathrm{mM})$ on AR development in cucumber explants. The values [mean \pm standard error (SE)] are the average of three independent experiments $(n=30$ explants per replicate). Values not sharing the same letters in the same list were significantly different by Duncan's multiple-comparison test $(p<0.05)$. 


\subsection{Involvement of Glc in HRW-Regulated AR Development}

Our previous study found that HRW treatment could promote the formation of AR in cucumber, and the optimal concentration was 50\% [25], which were also used in this study. To analyze the roles of Glc in $\mathrm{H}_{2}$-regulated AR development, cucumber explants were treated with $50 \% \mathrm{HRW}, 0.10 \mathrm{mM}$ Glc and $0.10 \mathrm{mM}$ Glc inhibitor glucosamine (GlcN) alone or together (Figure 1). Cucumber explants treated with 50\% HRW or $0.10 \mathrm{mM} \mathrm{Glc}$ exhibited significant increase in root number and root length (Figure 1). Additionally, co-treatment with HRW and Glc significantly enhanced adventitious rooting in comparison with HRW or Glc treatment alone. When GlcN was added to HRW, the positive effects of HRW on rooting was weakened. GlcN treatment alone significantly inhibited adventitious rooting in comparison with the control (Figure 1). These results indicated that Glc might be involved in $\mathrm{H}_{2}$-promoted AR development in cucumber.
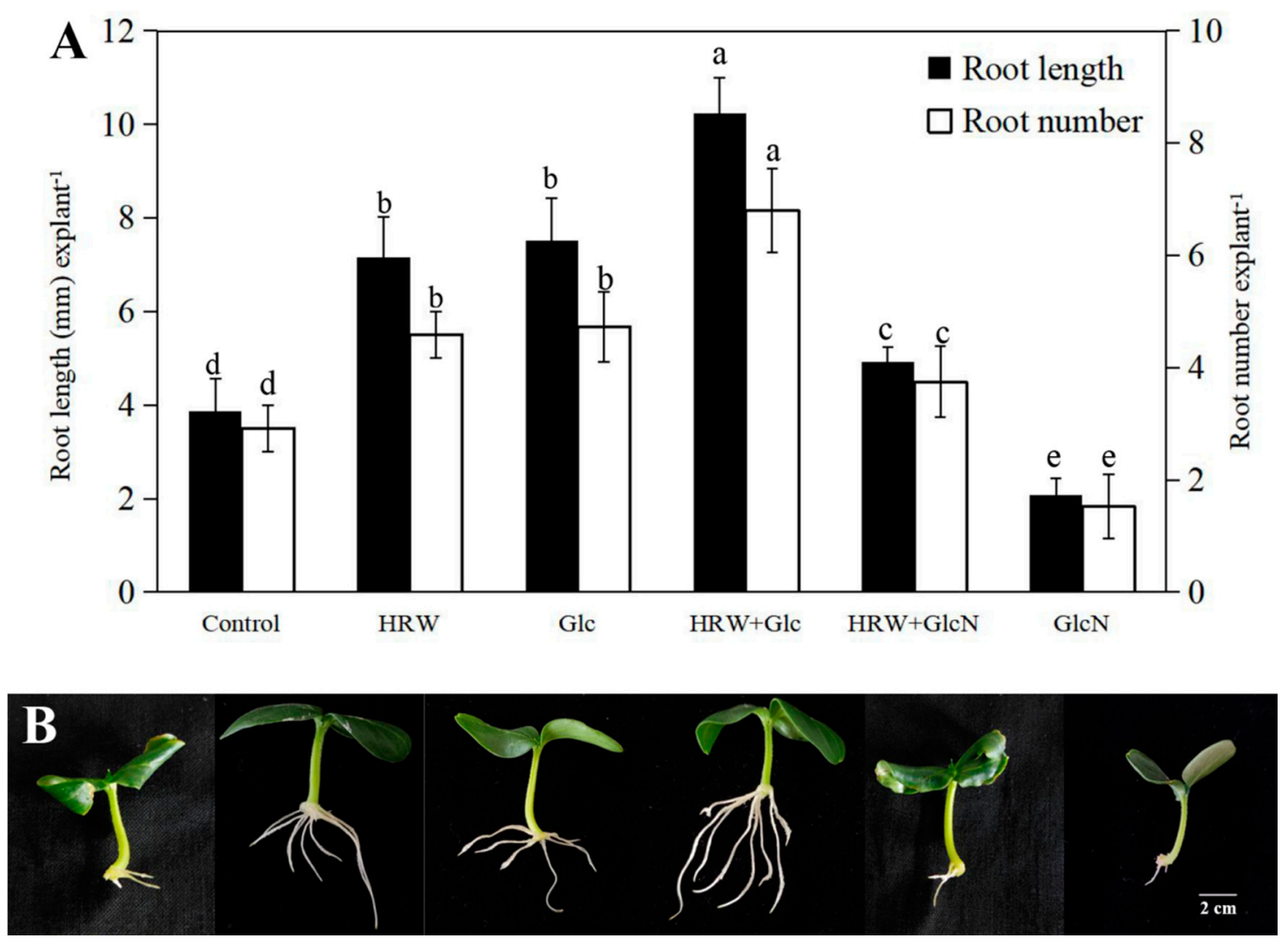

Figure 1. Effects of HRW, Glc and GlcN on root number and root length (A) and phenotype (B) of cucumber explants treated with $50 \% \mathrm{HRW}, 0.10 \mathrm{mM}$ Glc and $0.10 \mathrm{mM} \mathrm{GlcN}$ alone or together. $\mathrm{n}=30$ explants per replicate. Bars with different lower case letters were significantly different $(p<0.5)$. HRW: hydrogen rich water; Glc: glucose; GlcN: glucosamine.

\subsection{Effects of HRW, Glc and GlcN on Glucose, Sucrose, Starch and Total Sugar Contents during} Adventitious Rooting

Compared with the control, HRW and Glc treatments significantly increased the contents of glucose, sucrose, starch and total sugar (Figure 2). Additionally, glucose, sucrose, starch and total sugar contents in explants treated with HRW plus Glc were significantly increased compared to the HRW or Glc alone treatments. The glucose, sucrose, starch and total sugar contents in Glc inhibitor GlcN treatment were lower than that in the control (Figure 2). 


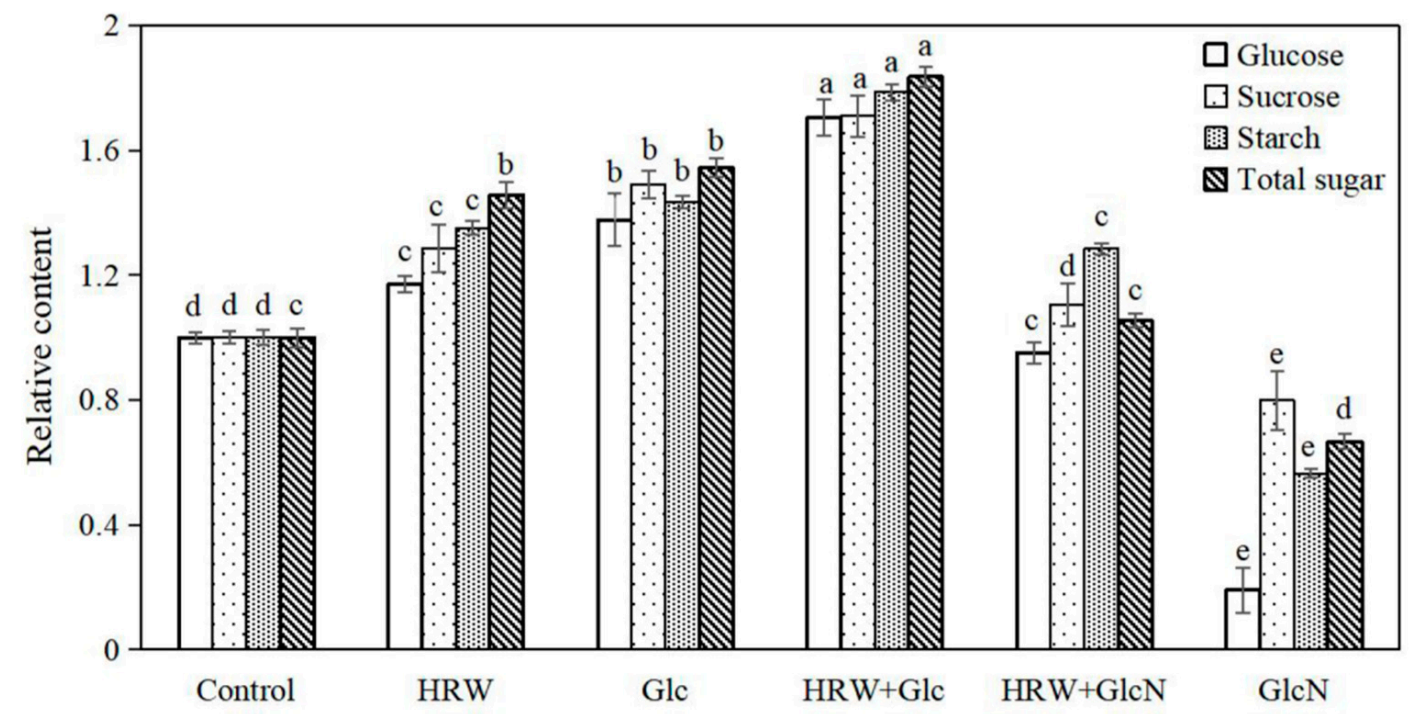

Figure 2. Effects of HRW, Glc and GlcN on glucose, sucrose, starch, and total sugar contents during adventitious rooting. $\mathrm{n}=30$ explants per replicate. Bars with different lower case letters were significantly different $(p<0.5)$. HRW: hydrogen rich water; Glc: glucose; GlcN glucosamine. The relative content (compared to the control) is displayed in the figure.

\subsection{Effects of HRW, Glc and GlcN on Hexose Phosphate Content during Adventitious Rooting}

As shown in Figure 3, HRW and Glc treatments significantly increased G6P, F6P and G1P contents compared with the control. In comparison with the separate treatment of HRW and Glc, HRW + Glc treatment significantly increased the contents of G6P, F6P and G1P. However, when GlcN was added, the positive impact of HRW on the G6P, F6P and G1P contents declined significantly (Figure 3 ). Compared with the control, GlcN alone treatment significantly decreased the contents of G6P, F6P and G1P (Figure 3).

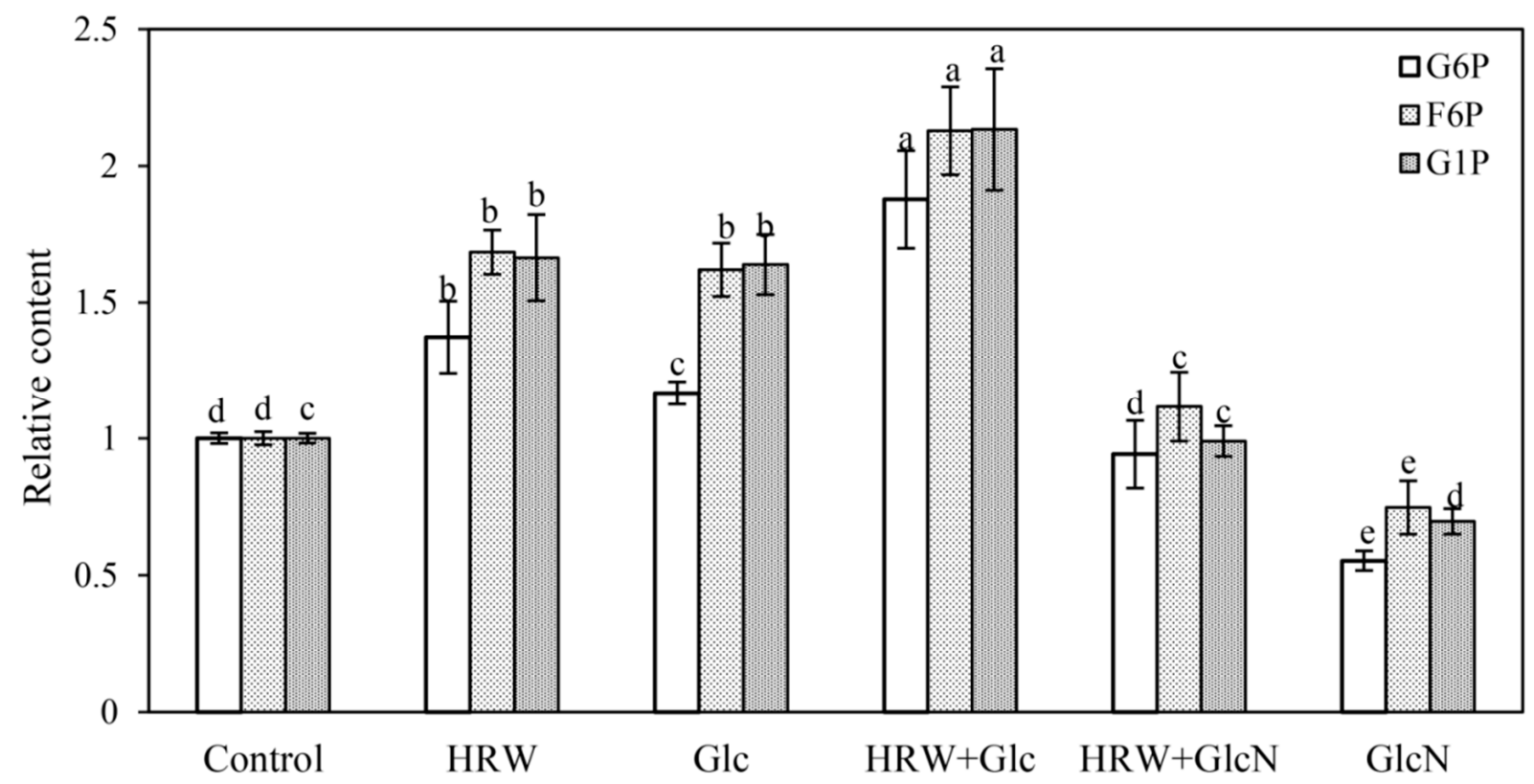

Figure 3. Changes in the contents of G6P, F6P and G1P of cucumber explants under the treatments of HRW, Glc and GlcN. $\mathrm{n}=30$ explants per replicate. Bars with different lower case letters were significantly different $(p<0.5)$. HRW: hydrogen rich water; Glc: glucose; GlcN: glucosamine; G6P: glucose-6-phosphate; F6P: fructose-6-phosphate; G1P: glucose-1-phosphate. The relative content (compared to the control) is displayed in the figure. 


\subsection{Effects of HRW, Glc and GlcN on Key Enzymes of Glucose Metabolism during Adventitious Rooting}

Compared to the control, the activities of SS, SPS, HK, PK and AGPase were significantly enhanced by Glc or HRW (Figure 4). Meanwhile, HRW plus Glc treatment showed higher SS, SPS, HK, PK and AGPase activities than HRW or Glc treatment (Figure 4). Conversely, GlcN significantly reduced the enhancement caused by HRW. The activities of SS, SPS, HK, PK and AGPase in GlcN treatment alone were lower than that in the control (Figure 4).

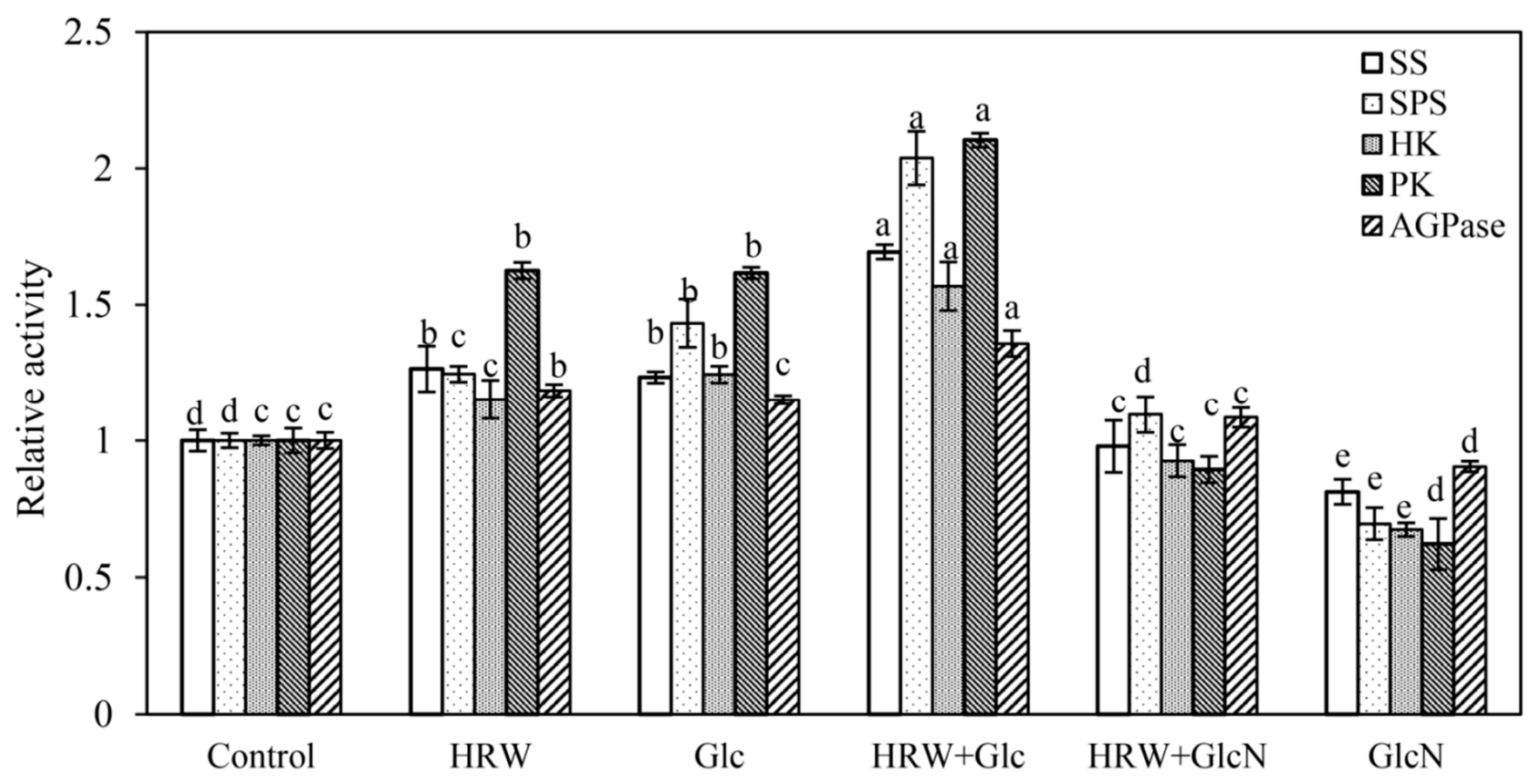

Figure 4. Effects of HRW, Glc and GlcN on SS, SPS, HK, PK and AGPase enzyme activities of cucumber explants. $\mathrm{n}=30$ explants per replicate. Bars with different lower case letters were significantly different $(p<0.5)$. HRW: hydrogen rich water; Glc: glucose; GlcN: glucosamine; SS: sucrose synthase; SPS: sucrose phosphate synthase; HK: hexokinase; PK: pyruvate kinase. AGPase: adenosine 5'-diphosphate pyrophosphorylase. The relative activity (compared to the control) is displayed in the figure.

2.6. Effects of HRW, Glc and GlcN on the Expression Levels of CsSuSy1, CsSuSy6, CsHK1, CsHK3, CsUDP1, CsUDP1-Like, CsG6P1 and CsG6P1-Like Genes during Adventitious Rooting

As shown in Figure 5, the expression levels of CsSuSy1, CsSuSy6, CsHK1, CsHK3, CsUDP1, CsUDP1-like, CsG6P1 and CsG6P1-like genes in Glc or HRW treatments were significantly upregulated in comparison with the control. Additionally, the expression levels of CsSuSy1, CsSuSy6, CsHK1, CsHK3, CsUDP1, CsUDP1-like, CsG6P1 and CsG6P1-like genes were the highest in HRW plus Glc treatment (Figure 5). Conversely, the expression levels of CsSuSy1, CsSuSy6, CsHK1, CsHK3, CsUDP1, CsUDP1-like, CsG6P1 and CsG6P1-like genes were significantly reduced when GlcN was added (Figure 5). 

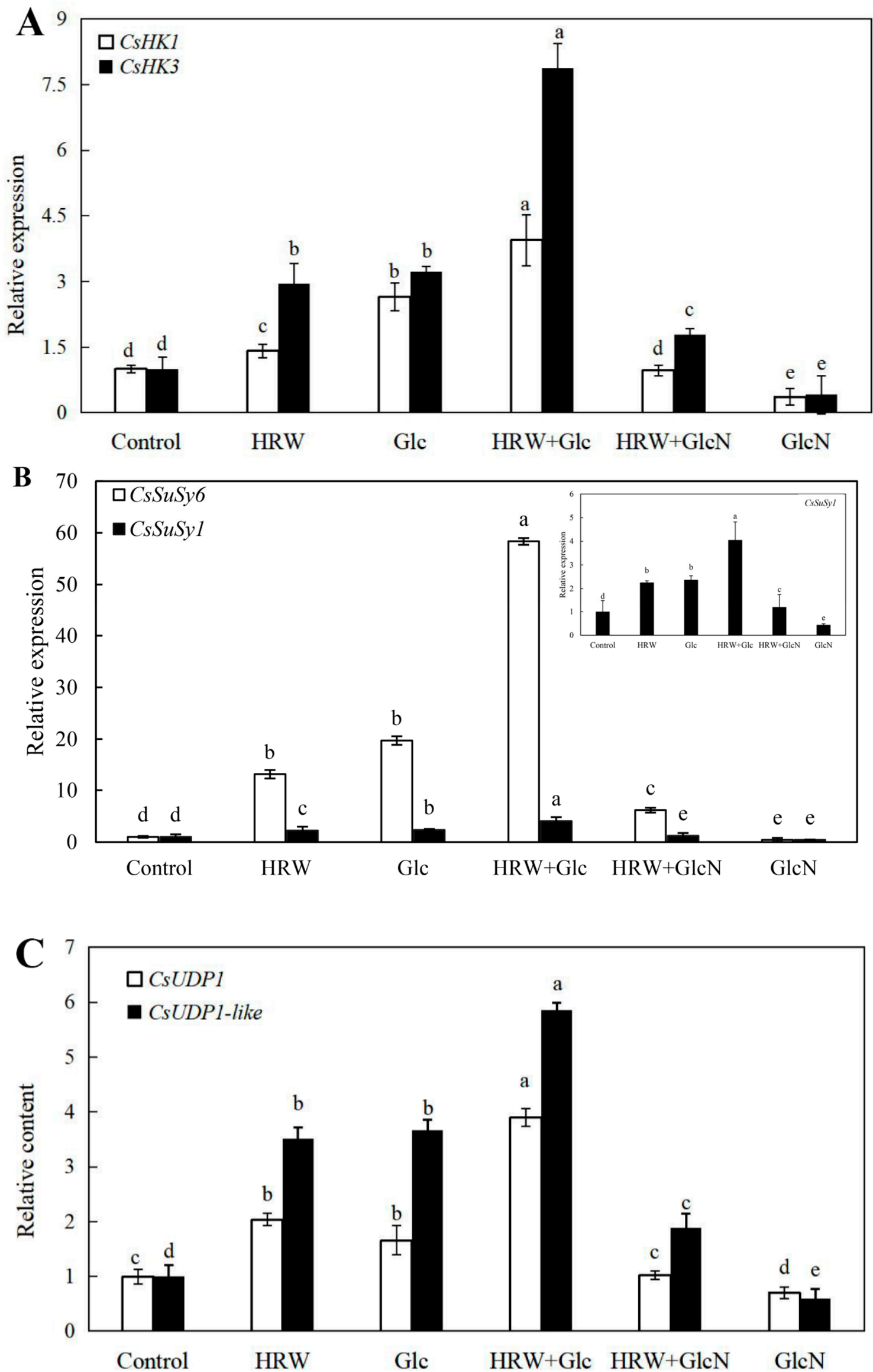

Figure 5. Cont. 


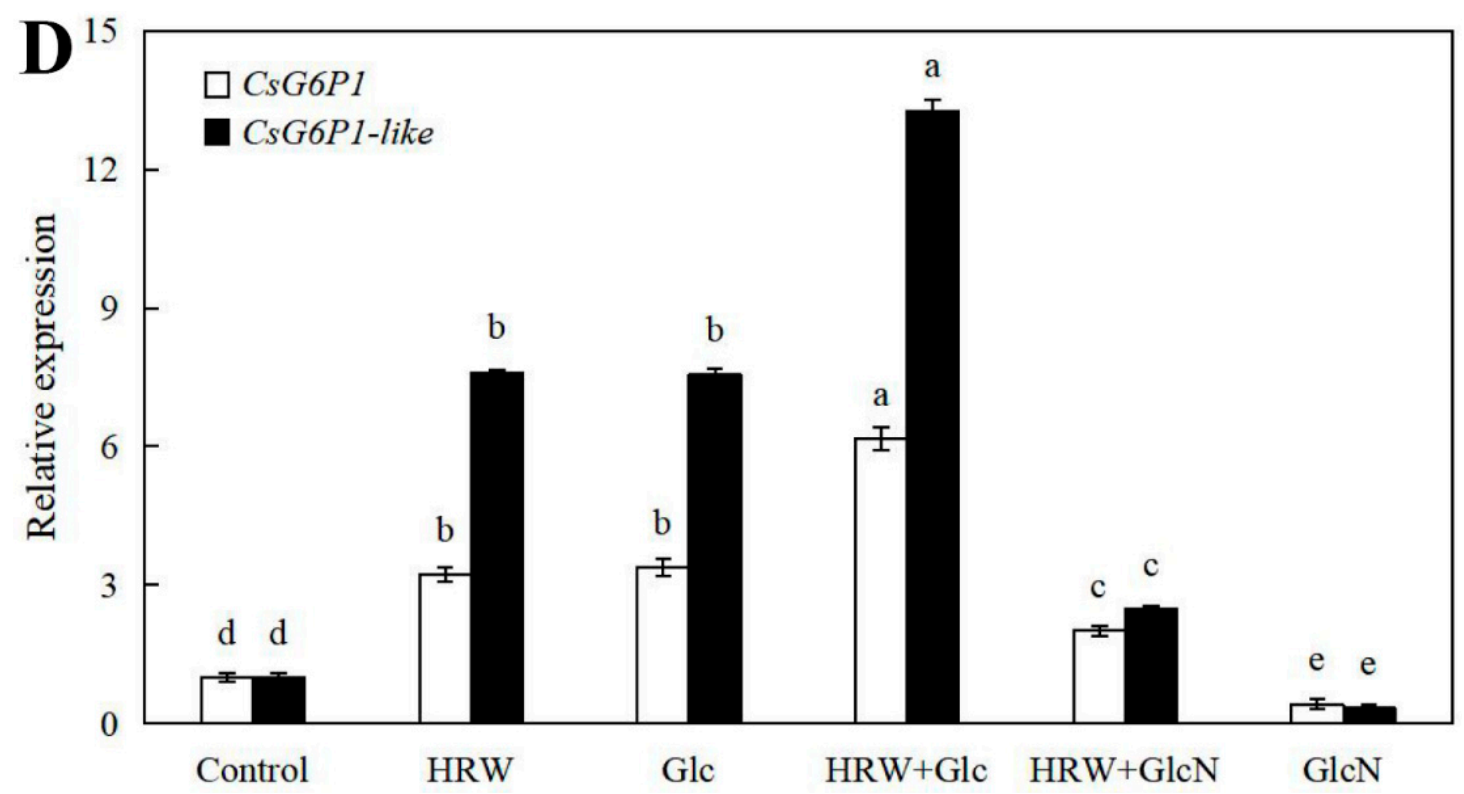

Figure 5. Effects of HRW, Glc and GlcN on the expression levels of CsSuSy1 and CsSuSy6 (A), CsHK1 and CsHK3 (B), CsUDP1 and CsUDP1-like (C), CsG6P1 and CsG6P1-like (D) genes in cucumber explants. $\mathrm{n}=30$ explants per replicate. Bars with different lower case letters were significantly different $(p<0.5)$. HRW: hydrogen rich water; Glc: glucose; GlcN: glucosamine.

\section{Discussion}

Generally, AR plays a vital role in nutrient and water absorption. Their formation is widely used for plant clonal propagation. Previous results in our lab have shown that $\mathrm{H}_{2}$ as a positive regulator regulated adventitious rooting in cucumber [26]. However, there is little research in the crosstalk between $\mathrm{H}_{2}$ and Glc during adventitious rooting. Here, we focus on the involvement of Glc in $\mathrm{H}_{2}$-regulated AR formation.

Glc as signaling molecule has been the concern of by many researchers. So far, accumulating evidence indicated that Glc participated in the regulation of various growth and development, such as seed germination, seedling development and fruit ripening [15]. In the present study, we illustrated that Glc treatment promoted adventitious rooting in cucumber explants in a dose-dependent manner, and $0.10 \mathrm{mM}$ Glc treatment was the most effective concentration (Table 1). Singh [27] reported that Glc controlled seedling root growth direction through regulating root waving and coiling in Arabidopsis thaliana, leading to altered root architecture. Mishra [24] also found that increasing Glc concentration increased root length, number of lateral roots and root hairs in Arabidopsis thaliana seedlings. Therefore, Glc plays a principal role in the regulation of root growth. A note of caution is that the effect of anaerobic bacteria on which glucose promoted adventitious rooting of cucumber has not been ruled out. Additionally, Zhu [16] found that NO was involved in $\mathrm{H}_{2}$-regulated adventitious rooting of cucumber. Chen [9] reported that $\mathrm{CO}$ was involved in $\mathrm{H}_{2}$-regulated adventitious rooting in cucumber under water stress. For the first time, our results indicated that Glc might be involved in $\mathrm{H}_{2}$-regulated AR development in cucumber (Figure 1). Therefore, signal molecules including nitric oxide (NO), carbon monoxide (CO) and Glc all were required for $\mathrm{H}_{2}$-regulated AR formation in cucumber.

In this study, we demonstrated, for the first time, that HRW treatment significantly increased the contents of glucose, sucrose, starch and total sugar during AR formation. However, the positive effects of HRW were blocked by GlcN (an inhibitor of Glu), suggesting that $\mathrm{H}_{2}$ might regulate adventitious rooting by increasing glucose, sucrose, starch and total sugar contents (Figure 2). However, the effect of $\mathrm{H}_{2}$ on sugar metabolism in plants has not yet been demonstrated so far. In animals, Kim and Kim [28] reported that application of HRW could improve blood glucose control for insulin deficiency and insulin resistance. HRW also has beneficial effects on lipid and glucose metabolism in humans [29]. 
Additionally, $\mathrm{CH}_{4}$-medicated starch and sucrose metabolism regulated bulblet formation in Lilium davidii var. unicolor [30]. Therefore, studies on $\mathrm{H}_{2}$ regulating glucose metabolism in plants need to be further explored. Glycolysis is a cytoplasmic pathway which breaks down glucose into G6P or F6P [17]. Glucose is trapped by phosphorylation, with the help of the enzyme hexokinase [17]. Our result found that Glc significantly increased G6P, F6P and G1P contents during adventitious rooting (Figure 3). Glc has also been shown to modulate hypocotyl directional growth in A. thaliana [27]. Here, we found that HRW also enhanced AR formation via increasing G6P, F6P and G1P contents. However, the positive role was inhibited by GlcN (Figure 3). Thus, $\mathrm{H}_{2}$ regulated adventitious rooting by increasing Glu, G6P, F6P and G1P contents.

Shi [31] revealed that SPS and SS were the key enzymes in sucrose accumulation in longan fruit. HK and PK played an essential role in Glc and fructose metabolism pathway [32]. Glc, via HK-dependent and -independent signal transduction, not only regulated root growth direction of vertically grown seedlings but also caused a significant drop in bending of roots under the stimulation of gravity in Arabidopsis Thaliana [33]. Starch is hydrolyzed into Glc during plant metabolism. AGPase is a key enzyme governing starch synthesis. In the study, HRW or Glc significantly enhanced the SS, SPS, HK, PK and AGPase enzyme activities. Conversely, GlcN significantly inhibited the enhancement caused by HRW (Figure 4). These results suggested that $\mathrm{H}_{2}$ promoted $\mathrm{AR}$ formation by enhancing the SS, SPS, HK, PK and AGPase enzyme activities. Kadowaki [34] reported that the activity of AGPase was also enhanced by sugar solution injections compared to the control, suggesting that the injection of sugar solutions is concluded to have a dual effect on root production in sweet potato. AGPase activity and production in roots was enhanced by injecting sucrose solution [35]. SuSy1 played an important role in maintaining sucrose concentration in the cytoplasm of kiwifruit [9]. In A. Thaliana, AtHK1 accelerated senescence, enhanced the appearance of lateral buds and affected root growth [36]. AtHK3 knockout mutant was found to be insensitive to $7 \%$ glucose, indicating that HK3 may play a role in sugar-sensing [37]. Transgenic rice plants overexpressing OsHXK5 or OsHXK6 exhibited growth inhibition and reduced expression of photosynthetic genes in response to glucose treatment [38]. We also found that HRW treatments were able to regulate higher expression levels of the sucrose metabolism-related genes including CsSuSy1 and CsSuSy6, and glucose metabolism-related genes including CsHK1, CsHK3, CsUDP1, CsUDP1-like, CsG6P1 and CsG6P1-like during AR formation (Figure 5). However, the upregulated gene expression was downregulated by GlcN (Figure 5). As mentioned above, $\mathrm{H}_{2}$ regulated AR formation by increasing the activities of SPS, SS, HK and PK enzymes and upregulating the expression levels of CsSuSy1, CsSuSy6, CsHK1, CsHK3, CsUDP1, CsUDP1-like, CsG6P1 and CsG6P1-like.

\section{Materials and Methods}

\subsection{Plant Material}

The seeds of cucumber (Cucumis sativus L. 'Xinchun NO. $4^{\prime}$ ) were soaked in 5\% sodium hypochlorite solution for disinfection and immersed in distilled water for $6 \mathrm{~h}$. The seeds were then transferred to a light incubator and maintained at $25 \pm 1{ }^{\circ} \mathrm{C}$ for 6 days with a 14-h photoperiod at $200 \mu \mathrm{mol} \cdot \mathrm{s}^{-1} \cdot \mathrm{m}^{-2}$ intensity. The 6 day-old cucumber seedings whose primary roots were removed and used as explants were then placed in Petri dishes with distilled water or different chemicals indicated below under the same conditions of temperature and photoperiod described above for another 5 days. The treatment solutions are replaced every $8 \mathrm{~h}$. Five days later, the number and length of AR per explant were measured and recorded. In addition, the explants were cultivated with different treatments under the same temperature and photoperiod conditions for $48 \mathrm{~h}$. The stage belongs to the induction process without roots. Therefore, the hypocotyl base $(1 \mathrm{~cm})$ was collected and used for the following analysis. 


\subsection{The Preparation of Hydrogen-Rich Water}

Purified $\mathrm{H}_{2}(99.99 \%, v / v)$ was generated from a $\mathrm{H}_{2}$-producing apparatus (QL-300, Saikesaisi Hydrogen Energy Co., Ltd., Jinan, China). Firstly, prepared hydrogen gas was bubbled into $2 \mathrm{~L}$ distilled water (room temperature) at a rate of $300 \mathrm{~mL} \cdot \mathrm{min}^{-1}$. The processing was continued for $3 \mathrm{~h}$. The prepared HRW was then analyzed by a dissolved hydrogen portable meter (ENH-1000, Trustlex Co., Led, Tokyo, Japan). The concentration of $\mathrm{H}_{2}$ was $0.45 \mathrm{mM}$, which was defined as $100 \%$ hydrogen rich water (HRW). Finally, HRW was immediately diluted to the required different concentrations $(0.5 \%, 1 \%, 5 \%, 10 \%, 50 \%$ and $100 \%)$.

\subsection{Explant Treatments}

Cucumber explants were cultivated with various concentrations of Glc $(0,0.01,0.05$, $0.10,0.50$ and $1.00 \mathrm{mM}$ ). In addition, GlcN as the inhibitor of glucose was used in the study; refer to Woodward [39] research. The following chemicals were carried out: control (distilled water), 50\% HRW, $0.10 \mathrm{mM} \mathrm{Glc,} \mathrm{50 \%} \mathrm{HRW} \mathrm{+} 0.10 \mathrm{mM}$ Glc and $0.10 \mu \mathrm{M} \mathrm{GlcN}$. Each process was set to three replicates. According to the initial experimental results, the concentration of the relevant chemical substance was determined.

\subsection{Determination Glucose Content}

Glucose was analyzed as described by Abdellatif with some modifications [33]. Briefly, a $0.5 \mathrm{~g}$ sample was homogenized with $10 \mathrm{~mL}$ distilled water, diluted with distilled water into $50 \mathrm{~mL}$ volumetric flask and then mixed. The volumetric flask was then placed into a $50{ }^{\circ} \mathrm{C}$ water bath kettle for $10 \mathrm{~min}$. Furthermore, 3,5-dinitrosalicylic acid (DNS) regent was prepared: 3,5-dinitrosalicylic acid (6.3 g) was dissolved in $262 \mathrm{~mL} 2 \mathrm{M}$ sodium hydroxide solution. The hot-water solution of $500 \mathrm{~mL}$ containing $185 \mathrm{~g}$ potassium sodium tartrate was added. The two solutions were mixed until solvents were dissolved, followed by adding $5 \mathrm{~g}$ redistilled phenol and $5 \mathrm{~g}$ sodium sulfite, mixed and cooled to room temperature, and the volume adjusted to exactly $1000 \mathrm{~mL}$ with distilled water. The supernatant $(2 \mathrm{~mL})$ and $1.5 \mathrm{~mL}$ of DNS were mixed together. The mixture was centrifuged at $4000 \mathrm{r} \cdot \mathrm{min}^{-1}$ at $4{ }^{\circ} \mathrm{C}$ for $15 \mathrm{~min}$. It was then placed in a boiling water bath for $5 \mathrm{~min}$, cooled to room temperature, and then filtered into a $25 \mathrm{~mL}$ volumetric flask. The absorbance value was measured at $540 \mathrm{~nm}$ and the data were recorded. The relative content (compared to the control) is shown in Figure 2.

\subsection{Determination Sucrose Content}

The sucrose content was analyzed according to the procedure of Tauzin [40] making appropriate modifications according to experimental requirements. The sample $(1.0 \mathrm{~g})$ was homogenized with $10 \mathrm{~mL}$ of $80 \%$ ethanol and diluted with distilled water in a $100 \mathrm{~mL}$ volumetric flask. The volumetric flask was placed in a water bath at a constant temperature of $80^{\circ} \mathrm{C}$ for $45 \mathrm{~min}$, allowed to cool to room temperature and then filtered with a quantitative analysis filter paper with a diameter of $9 \mathrm{~cm}$. The filter liquor was collected as the reaction liquid. The filter $(0.4 \mathrm{~mL})$ was mixed with $0.2 \mathrm{~mL} 2 \mathrm{M} \mathrm{NaOH}$ and bathed for $10 \mathrm{~min}$ at $80^{\circ} \mathrm{C}$; after cooling to room temperature, measurement of absorbance at $540 \mathrm{~nm}$ was carried out. The relative content (compared to the control) is shown in Figure 2.

\subsection{Determination Starch Content}

The method described by Smith was adopted to determine the starch content [41]. The frozen sample $(0.5 \mathrm{~g})$ was ground with $2 \mathrm{~mL}$ distilled water. Furthermore, $3.2 \mathrm{~mL}$ of $60 \%$ $\mathrm{HClO} 4$ was added. The solution was transferred to a $10 \mathrm{~mL}$ tube, diluted with distilled water to volume, and mixed. The solution was then centrifuged at $5000 \mathrm{r} \cdot \mathrm{min}^{-1}$ for $5 \mathrm{~min}$, filtered and diluted with distilled water to $100 \mathrm{~mL}$ volumetric flask and mixed. The sucked supernatant $(0.5 \mathrm{~mL})$ was diluted to $3 \mathrm{~mL}$ with distilled water. Iodine reagent $(2 \mathrm{~mL})$ was added, mixed and left to stand for $5 \mathrm{~min}$. Finally, it was diluted with distilled water to 
$10 \mathrm{~mL}$. Distilled water was used as control and the absorbance was measured at $660 \mathrm{~nm}$. The relative content (compared to the control) is shown in Figure 2.

\subsection{Determination Total Sugar Content}

Total sugar content was determined by procedures described according to Nath [42]. The $10 \mathrm{~mL} 6 \mathrm{M} \mathrm{HCl}$ was added to a $25 \mathrm{~mL}$ stopper tube to which $1 \mathrm{~g}$ sample was homogenized, and diluted to $25 \mathrm{~mL}$ with distilled water. The sugar was hydrolyzed during a $30 \mathrm{~min}$ water bath. Using phenolphthalein as its indicator, the total sugar content was determined with $6 \mathrm{M} \mathrm{NaOH}$ standard titration solution. Volume was then adjusted with distilled water to $100 \mathrm{~mL}$, mixed and filtered. The filter liquor $(10 \mathrm{~mL})$ was transferred to a new test tube. It was then diluted to $100 \mathrm{~mL}$ with aqua distillate and analyzed. The absorbance value was measure at $540 \mathrm{~nm}$ and the data were recorded. The relative content (compared to the control) is shown in Figure 2.

\subsection{Hexose Phosphate Content Measurements}

Enzyme liquid was extracted by the modified method of Nägele and Wolfram [43]. In a nutshell, $0.5 \mathrm{~g}$ samples were ground in liquid nitrogen, then added to $2 \mathrm{~mL} 5 \%$ trichloroacetic acid (TCA) consisting of $100 \mathrm{mg}$ PVPP. The mixtures were centrifuged at $12,000 \mathrm{r} \cdot \mathrm{min}^{-1}$ for $15 \mathrm{~min}$ at $4{ }^{\circ} \mathrm{C}$. The supernatant was collected, and $150 \mu \mathrm{L}$ neutralizing buffer containing $1 \mathrm{M}$ triethanolamine and $5 \mathrm{M}$ potassium hydroxide $(\mathrm{KOH})$ was added to the supernatant. After a reaction for $30 \mathrm{~min}$ on ice, the mixture was then centrifuged at $12,000 \mathrm{r} \cdot \mathrm{min}^{-1}$ for $15 \mathrm{~min}$. The supernatants were collected as the crude extract used for further analysis.

For G6P, F6P and glucose-1-phosphate (G1P), the reaction mixture consisted of $497 \mu \mathrm{L}$ distilled water, $100 \mu \mathrm{L} 1 \mathrm{M}$ Hepes-KOH (pH 7.6), $100 \mu \mathrm{L} 50 \mathrm{mM} \mathrm{MgCl} 2,100 \mu \mathrm{L} 4 \mathrm{mM}$ NAD, $100 \mu \mathrm{L} 10 \mathrm{mM}$ EDTA and $100 \mu \mathrm{L}$ of the above crude extract. The formation of blue formazan was monitored by recording the absorbance at $560 \mathrm{~nm}$. G6PDH, PGI and PGM were added successively for G6P, F6P and G1P mixtures, and then were determined by measuring the absorbance at $340 \mathrm{~nm}$. The relative content (compared to the control) is shown in Figure 3.

\subsection{SS, SPS, HK and PK AGPase Enzymes Activity Measurement}

Enzyme extracts were performed as described previously [31]. Samples were harvested, ground in liquid nitrogen and homogenized in ice-cold $9 \mathrm{~mL}$ PBS $(\mathrm{pH}=7.4)$. Extracts were then centrifuged at $3000 \mathrm{r} \cdot \mathrm{min}^{-1}$ for $15 \mathrm{~min}$ at $4{ }^{\circ} \mathrm{C}$. The activities of sucrose synthase (SS), sucrose phosphate synthase (SPS), HK, pyruvate kinase (PK), and AGPase enzymes were measured by enzyme-linked immunosorbent assay (ELISA; AndyGene Biotechnology Co. Ltd., Beijing, China) according to the manufacturer's instructions. The relative activity (compared to the control) is shown in Figure 4

\subsection{Quantitative Real-Time PCR ( $q R T-P C R)$}

Total RNA was extracted using TRIzol (Invitrogen Life Technologies) by using the method described by Huang [44]. RNA was reverse transcribed with the $5 \times E v o$ M-MLVRT Master Mix (AG, China) according to the manufacturer's instructions. Csactin [35] was used as an internal control to calculate the relative expression. The relative transcript expression levels of the genes were quantified using $2^{-\Delta \Delta c t}$. The Cdna was amplified with $2 \times$ SYBR Green Pro Taq HS Premix (AG, China) using the following primers shown in Table 2. The reactions were controlled by the following conditions: $30 \mathrm{~s}$ at $95^{\circ} \mathrm{C}$, then $5 \mathrm{~s}$ at $95^{\circ} \mathrm{C}$ and $30 \mathrm{~s}$ at $60^{\circ} \mathrm{C}$ for 40 cycles. 
Table 2. Sequences of primers used for RT-PCR analysis.

\begin{tabular}{|c|c|c|}
\hline Gene Symbol & Accession Number ${ }^{a}$ & Primer Sequence $\left(5^{\prime}-3^{\prime}\right)$ \\
\hline CsSuSy1-F & LOC101213767 & CGTGTGCTAAGGAAGGCGGAAG \\
\hline CsSuSy1-R & & CAGTGTCACCССАСССТСТСТC \\
\hline CsSuSy6-F & LOC101216865 & TCCAACCGCCACAACTTCATCAC \\
\hline CsSuSy6-R & & CСATTCССАСТCTGCCCAAGC \\
\hline CsHK1-F & LOC101218300 & CGCCATGACCGTCGAGATGC \\
\hline CsHK1-R & & TTTGTACCGCCGAGATCCAATGC \\
\hline CsHK3-F & LOC101215511 & CACGGTCCTAGTCAGTCGGAGAG \\
\hline CsHK3-R & & GCCATAGCATCAACCACCTGTCTC \\
\hline CsUDP1-F & LOC101206505 & TCCAGAGTTCCTTGCTGAGGGTAC \\
\hline CsUDP1-R & & AAGCCTGAATTGCCTTGAGACCATC \\
\hline CsUDP1-like-F & LOC116401645 & AGTTAATGCCATTTCCGCCCTCTG \\
\hline CsUDP1-like-R & & TCTTGTATCCGTACCAACCGAATGC \\
\hline CsG6P1-F & LOC101222586 & AGGTGCGATTGCTAATCCAGATGAG \\
\hline CsG6P1-R & & TGCGACTTCAAGAACGAGTTAGGTG \\
\hline CsG6P1-like-F & LOC101210696 & AGGGTGGAGGTTTAGGGTTTAGGG \\
\hline CsG6P1-like-R & & GCCGCTCGTTCATTCCATTGTTC \\
\hline
\end{tabular}

\subsection{Data Statistics and Analysis}

Where indicated, results were expressed as the mean values $\pm \mathrm{SE}$ of at least three independent experiments and 30 explants were taken for each replicate. Statistical analysis was performed using SPSS 22.0. For statistical analysis, Duncan's multiple test $(p<0.05)$ was chosen as appropriate.

\section{Conclusions}

The present study provides new insights into the roles and interactions of $\mathrm{H}_{2}$ and Glc in the AR development in cucumber. It can be concluded that the $\mathrm{H}_{2}$ increased the glucose, sucrose, starch, total sugar, G6P, F6P and G1P contents during adventitious rooting. Meanwhile, the sucrose-related enzymes, including SS and SPS, and glucose-related enzymes, including $\mathrm{HK}, \mathrm{PK}$ and AGPase activities, were increased by $\mathrm{H}_{2}$. Meanwhile, $\mathrm{H}_{2}$ also upregulated the expression levels of sucrose or glucose metabolism-related genes including CsSuSy1, CsSuSy6, CsHK1, CsHK3, CsUDP1, CsUDP1-like, CsG6P1 and CsG6P1-like. In conclusion, Glc might be responsible for $\mathrm{H}_{2}$-regulated $\mathrm{AR}$ development.

Author Contributions: Conceptualization, W.L.; data curation, C.L. and P.H.; funding acquisition, W.L.; investigation, Z.Z.; methodology, C.L., H.L. and J.Y.; writing-original draft, Z.Z.; writingreview and editing, W.L. All authors have read and agreed to the published version of the manuscript.

Funding: This work was supported by the National Natural Science Foundation of China (Nos. 32072559, 31860568, 31560563, and 31160398); the Research Fund of Higher Education of Gansu, China (Nos. 2018C-14 and 2019B-082); and the Natural Science Foundation of Gansu Province, China (Nos. 1606RJZA073, 1606RJZA077, and 1606RJYA252).

Institutional Review Board Statement: Not applicable.

Informed Consent Statement: Not applicable.

Data Availability Statement: All data, tables and figures in this manuscript are original.

Conflicts of Interest: The authors declare no conflict of interest.

\section{References}

1. De Klerk, G.J.; Van Der Krieken, W.; De Jong, J.C. Review the formation of adventitious roots: New concepts, new possibilities. Vitr. Cell. Dev. Biol. Plant 1999, 35, 189-199. [CrossRef]

2. Li, S.W.; Leng, Y.; Feng, L.; Zeng, X.Y. Involvement of abscisic acid in regulating antioxidative defense systems and IAA-oxidase activity and improving adventitious rooting in mung bean [Vigna radiata (L.) Wilczek] seedlings under cadmium stress. Environ. Sci. Pollut. Res. 2014, 21, 525-537. [CrossRef] [PubMed] 
3. Pop, T.I.; Pamfil, D.; Bellini, C. Auxin control in the formation of adventitious roots. Not. Bot. Horti. Agrobo. 2011, 39, 307-316. [CrossRef]

4. Kwak, M.S.; Kim, I.H.; Kim, S.K.; Han, T.J. Effects of brassinolide with naphthalene acetic acid on the formation of adventitious roots, trichome-like roots and calli from cultured tobacco leaf segments, and the expression patterns of CNT103. J. Plant Biol. 2009, 52, 511. [CrossRef]

5. Steffens, B.; Wang, J.X.; Sauter, M. Interactions between ethylene, gibberellin and abscisic acid regulate emergence and growth rate of adventitious roots in deepwater rice. Planta 2006, 223, 604-612. [CrossRef] [PubMed]

6. Rasmussen, A.; Hu, Y.M.; Depaepe, T.; Vandenbussche, F.; Boyer, D.F.; Geelen, D. Ethylene controls adventitious root initiation sites in arabidopsis hypocotyls independently of strigolactones. J. Plant Growth Regul. 2017, 36, 897-911. [CrossRef]

7. Takáč, T.; Obert, B.; Rolčík, J.; Šamaj, J. Improvement of adventitious root formation in flax using hydrogen peroxide. New Biotechnol. 2016, 33, 728-734. [CrossRef]

8. Jin, X.; Liao, W.B.; Yu, J.H.; Ren, P.J.; Dawuda, M.M.; Wang, M.; Niu, L.J.; Li, X.P.; Xu, X.T. Nitric oxide is involved in ethyleneinduced adventitious rooting in marigold (Tagetes erecta L.). CAN. J. Plant Sci. 2017, 97, 620-631.

9. Chen, Y.; Wang, M.; Hu, L.L.; Liao, W.B.; Dawuda, M.M.; Li, C.L. Carbon monoxide is involved in hydrogen gas-induced adventitious root development in cucumber under simulated drought stress. Front. Plant Sci. 2017, 8, 128. [CrossRef]

10. Lin, Y.T.; Li, M.Y.; Cui, W.T.; Lu, W.; Shen, W.B. Haem oxygenase-1 is involved in hydrogen sulfide-induced cucumber adventitious root formation. J. Plant Growth Regul. 2012, 31, 519-528. [CrossRef]

11. Bai, T.H.; Dong, Z.D.; Zheng, X.B.; Song, S.W.; Jiao, J.; Wang, M.M.; Song, C.H. Auxin and its interaction with ethylene control adventitious root formation and development in apple rootstock. Front. Plant Sci. 2020, 11, 574881. [CrossRef] [PubMed]

12. Tian, R.F.; Hou, Z.; Hao, S.Y.; Wu, W.C.; Mao, X.; Tao, X.G.; Lu, T.; Liu, B.Y. Hydrogen-rich water attenuates bran damage inflammation after traumatic brain injury in rats. Brain Res. 2016, 1637, 1-13. [CrossRef] [PubMed]

13. Ostojic, S.M. Molecular hydrogen in sports medicine: New therapeutic perspectives. Int. J. Sports Med. 2015, 36, 273-279. [CrossRef]

14. Li, C.X.; Gong, T.Y.; Bian, B.T.; Liao, W.B. Roles of hydrogen gas in plants: A review. Funct. Plant Biol. 2018, 45, 783-792. [CrossRef] [PubMed]

15. Hu, H.L.; Li, P.X.; Wang, Y.N.; Gu, R.X. Hydrogen-rich water delays postharvest ripening and senescence of kiwifruit. Food Chem. 2014, 156, 100-109. [CrossRef] [PubMed]

16. Zhu, Y.C.; Liao, W.B.; Niu, L.J.; Wang, M.; Ma, Z.J. Nitric oxide is involved in hydrogen gas-induced cell cycle activation during adventitious root formation in cucumber. BMC Plant Biol. 2016, 16, 146. [CrossRef]

17. Rolland, F.; Baena-Gonzalez, E.; Sheen, J. Sugar sensing and signaling in plants: Conserved and novel mechanisms. Annu. Rev. Plant Biol. 2006, 57, 675-709. [CrossRef]

18. Xiao, W.Y.; Sheen, J.; Jang, J.C. The role of hexokinase in plant sugar signal transduction and growth and development. Plant Mol. Biol. 2000, 44, 451-461. [CrossRef]

19. Sturm, A. Invertases. Primary structures, functions, and roles in plant development and sucrose partitioning. Plant Physiol. 1999, 121, 1-8. [CrossRef]

20. Ren, X.D.; Zhang, J.J. Research progresses on the key enzymes involved in sucrose metabolism in maize. Carbohydr. Res. 2013, 368, 29-34. [CrossRef]

21. Das, A.; Rushton, P.J.; Rohila, J.S. Metabolomic profiling of soybeans (Glycine max L.) reveals the importance of sugar and nitrogen metabolism under drought and heat stress. Plants 2017, 6, 21. [CrossRef]

22. Gibson, S.I. Control of plant development and gene expression by sugar signaling. Curr. Opin. Plant Biol. 2005, 8, 93-102. [CrossRef]

23. Saksena, H.B.; Sharma, M.; Singh, D.; Laxmi, A. The versatile role of glucose signalling in regulating growth, development and stress responses in plants. J. Plant Biochem. Biot. 2020, 29, 687-699. [CrossRef]

24. Mishra, B.S.; Singh, M.; Aggrawal, P.; Laxmi, A. Glucose and auxin signaling interaction in controlling Arabidopsis thaliana seedlings root growth and development. PLOS ONE 2009, 4, e4502. [CrossRef] [PubMed]

25. Li, C.X.; Bian, B.T.; Gong, T.Y.; Liao, W.B. Comparative proteomic analysis of key proteins during abscisic acid-hydrogen peroxide-induced adventitious rooting in cucumber (Cucumis sativus L.) under drought stress. J. Plant Physiol. 2018, 229, 185-194. [CrossRef]

26. Li, C.X.; Huang, D.J.; Wang, C.L.; Wang, N.; Liao, W.B. No is involved in $\mathrm{h}_{2}$-induced adventitious rooting in cucumber by regulating the expression and interaction of plasma membrane h+-atpase and 14-3-3. Planta 2020, 252, 9. [CrossRef] [PubMed]

27. Singh, M.; Gupta, A.; Laxmi, A. Glucose control of root growth direction in Arabidopsis thaliana. J. Epx. Bot. 2014, 65, 2981-2993. [CrossRef] [PubMed]

28. Kim, M.J.; Kim, H.K. Anti-diabetic effects of electrolyzed reduced water in streptozotocin-induced and genetic diabetic mice. Life Sci. 2006, 79, 2288-2292. [CrossRef]

29. Kajiyama, S.; Hasegawa, G.; Asano, M.; Hosoda, H.; Fukui, M.; Nakamura, N.; Kitawaki, J.; Imai, S.; Nakano, K.; Ohta, M.; et al. Supplementation of hydrogen-rich water improves lipid and glucose metabolism in patients with type 2 diabetes or impaired glucose tolerance. Nutr. Res. 2008, 28, 137-143. [CrossRef] [PubMed] 
30. Qi, N.N.; Hou, X.M.; Wang, C.L.; Li, C.X.; Huang, D.J.; Li, Y.H.; Wang, N.; Liao, W.B. Methane-rich water induces bulblet formation of scale cuttings in Lilium davidii var. unicolor by regulating the signal transduction of phytohormones and their levels. Physiol. Plant. 2021, 172, 1919-1930. [CrossRef]

31. Shi, S.Y.; Wang, W.; Liu, L.Q.; Shu, B.; Wei, Y.Z.; Jue, D.W.; Fu, J.X.; Xie, J.H.; Liu, C.M. Physico-chemical properties of longan fruit during development and ripening. Sci. Hortic. 2016, 207, 160-167. [CrossRef]

32. Gupta, A.; Singh, M.; Laxmi, A. Multiple interactions between glucose and brassinosteroid signal transduction pathways in Arabidopsis are uncovered by Whole-Genome transcriptional profiling. Plant Physiol. 2015, 168, 1091-1105. [CrossRef]

33. Bhaji, A.; Li, J.; Ovecka, M.; Ezquer, L.; Muñoz, F.J.; Baroja-Fernández, E.; Romero, J.M.; Almagro, G.; Montero, M.; Hidalgo, M.; et al. Arabidopsis thaliana mutants lacking ADP-glucose pyrophosphorylase accumulate starch and wild-type ADP-glucose content: Further evidence for the occurrence of important sources, other than ADP-glucose pyrophosphorylase, of ADP-glucose linked to leaf starch. Plant Cell Physiol. 2011, 52, 1162-1176. [CrossRef] [PubMed]

34. Kadowaki, M.; Kubota, F.; Saitou, K. Effects of exogenous injection of different sugars on leaf photosynthesis, dry matter production and adenosine 5'-diphosphate glucose pyrophosphorylase (AGPase) activity in sweet potato, ipomoea batatas (Lam.). J. Agron. Crop Sci. 2010, 186, 37-41. [CrossRef]

35. Tsubone, M.; Kubota, F.; Saitou, K.; Kadowaki, M. Enhancement of tuberous root production and adenosine 5'-diphosphate pyrophosphorylase (AGPase) activity in sweet potato (Ipomoea batatas Lam.) by exogenous injection of sucrose solution. $J$. Agron. Crop Sci. 2000, 184, 181-186. [CrossRef]

36. Moore, B.; Zhou, L.; Rolland, F.; Hall, Q.; Cheng, W.H.; Liu, Y.X.; Hwang, I.; Jones, T.; Sheen, J. Role of the Arabidopsis glucose sensor HXK1 in nutrient, light, and hormonal signaling. Science 2003, 300, 332-336. [CrossRef] [PubMed]

37. Kelly, G.; David-Schwartz, R.; Sade, N.; Moshelion, M.; Levi, A.; Alchanatis, V.; Granot, D. The pitfalls of transgenic selection and new roles of AtHXK1: A high level of AtHXK1 expression uncouples hexokinase1-dependent sugar signaling from exogenous sugar. Plant Physiol. 2012, 159, 47-51. [CrossRef] [PubMed]

38. Zhang, Z.W.; Yuan, S.; Xu, F.; Yang, H.; Zhang, N.H.; Cheng, J.; Lin, H.H. The plastid hexokinase pHXK: A node of convergence for sugar and plastid signals in Arabidopsis. FEBS Lett. 2010, 584, 3573-3579. [CrossRef]

39. Woodward, G.E.; Hudson, M.T. D-glucosamine as an antagonist of glucose in carbohydrate metabolism of yeast. J. Frankl. Inst. 1953, 255, 556-560. [CrossRef]

40. Tauzin, A.S.; Giardina, T. Sucrose and invertases, a part of the plant defense, response to the biotic stresses. Front. Plant Sci. 2014, 5, 293. [CrossRef]

41. Smith, A.M.; Zeeman, S.C. Quantification of starch in plant tissues. Nat. Protoc. 2006, 1, 1342-1345. [CrossRef]

42. Nath, K.; Mahatma, M.K.; Swami, R. Role of total soluble sugar, phenols and defense related enzymes in relation to banana fruit rot by lasiodiplodia theobromae [(path.) griff.and maubl.] during ripening. J. Plant Pathol. 2015, 6, 8.

43. Nägele, T.; Weckwerth, W. Mathematical modeling reveals that metabolic feedback regulation of SnRK1 and hexokinase is sufficient to control sugar homeostasis from energy depletion to full recovery. Plant Sci. 2014, 5, 365.

44. Huang, D.J.; Li, W.T.; Dawuda, M.M.; Huo, J.Q.; Wang, C.L.; Liao, W.B. Hydrogen sulfide reduced colour change in lanzhou lily-bulb scales. Postharvest Biol. Tec. 2021, 176, 111520. [CrossRef] 